Cinémas

Revue d'études cinématographiques

Journal of Film Studies

\title{
Kubrick as Architect
}

\section{Paolo Cherchi Usai}

Volume 9, numéro 1, automne 1998

Les Dispositifs de médiation au cinéma

URI : https://id.erudit.org/iderudit/024776ar

DOI : https://doi.org/10.7202/024776ar

Aller au sommaire du numéro

Éditeur(s)

Cinémas

ISSN

1181-6945 (imprimé)

1705-6500 (numérique)

Découvrir la revue

Citer cet article

Cherchi Usai, P. (1998). Kubrick as Architect. Cinémas, 9(1), 117-136.

https://doi.org/10.7202/024776ar

\section{Résumé de l'article}

Cet essai examine la pertinence éloquente des éléments d'architecture dans les films de Stanley Kubrick. Les propositions de Hermann Muthesius et Frank Lloyd Wright concernant les rapports entre la forme et l'architecture sont considérés comme une base théorique pour explorer les voies selon lesquelles des éléments comme les fenêtres, les cages d'escalier, les corridors et l'ornement prennent des fonctions symboliques et narratives chez Kubrick.
Ce document est protégé par la loi sur le droit d'auteur. L'utilisation des services d’Érudit (y compris la reproduction) est assujettie à sa politique d'utilisation que vous pouvez consulter en ligne.

https://apropos.erudit.org/fr/usagers/politique-dutilisation/ 


\title{
Kubrick as Architect ${ }^{1}$
}

\section{Paolo Cherchi Usai}

\author{
RÉSUMÉ
}

Cet essai examine la pertinence éloquente des éléments d'architecture dans les films de Stanley Kubrick. Les propositions de Hermann Muthesius et Frank Lloyd Wright concernant les rapports entre la forme et l'architecture sont considérés comme une base théorique pour explorer les voies selon lesquelles des éléments comme les fenêtres, les cages d'escalier, les corridors et l'ornement prennent des fonctions symboliques et narratives chez Kubrick.

\section{ABSTRACT}

This essay examines the expressive relevance of architectural elements in the films of Stanley Kubrick. The proposals of Hermann Muthesius and Frank Lloyd Wright concerning the relationships of function to form and of ornement to the architectural whole are considered as a theoretical ground for exploring the ways in which elements such as windows, staircases, corridors and ornament acquire symbolic and narrative functions in Kubrick.

But that which is born as arabesque, over time puts out nails and teeth; and after having pleasantly stimulated the skin, it even gnaws away at the vital parts. 


\section{In 1904 Hermann Muthesius wrote:}

[A modern] bathroom is like a scientific instrument, in which ingenious technique celebrates its triumph and where the introduction of any type of "art " would only seem to disturb. The pure form which derives from the functional purpose is in itself so ingenious and significant as to produce aesthetic enjoyment, which does not differ at all from the artistic sense.

"Art," in this case, is synonymous with "ornament" and opposed to "function." A building must first of all permit the carrying out of human activities which require space, light, protection and practicality. Once it has satisfied these requirements, an architectural construction has performed the fundamental part of its task.

This is a reasonable, elementary criterion, but it does not exhaust all hypotheses of distinction between what is "essential" in a building and all that is added to load-bearing structures, nor does it explain the presence, in organisms of vast proportions such as the Overlook Hotel (in The Shining, 1979) or the spaceship Discovery (in 2001: A Space Odyssey, 1968), of plastic and figurative elements which do not depend upon the functional requirements of architectural constructions or on a determining expressive relevance. As for ornament - by definition a superfluous addition to the statics of load-bearing structures - its passive role with regards to the principle of function appears, from the beginning, to be a given. And yet Muthesius often prescribes it as a symbol of identification between the part and the whole, in open polemic with the position of Adolf Loos, which champions the "ascetic" refusal of mosaic decoration.

The definition of ornament drawn from common usage is subject to serious objections. Of particular importance is the observation that the functional criterion - the quantity of needs which the building must satisfy - is not only a technical value but also, in a particular manner, behavioural. The handle of a door permits the individual to pass from one room to another in a house. A well-finished door handle is not necessarily the instrument favouring the most rapid execution of this 


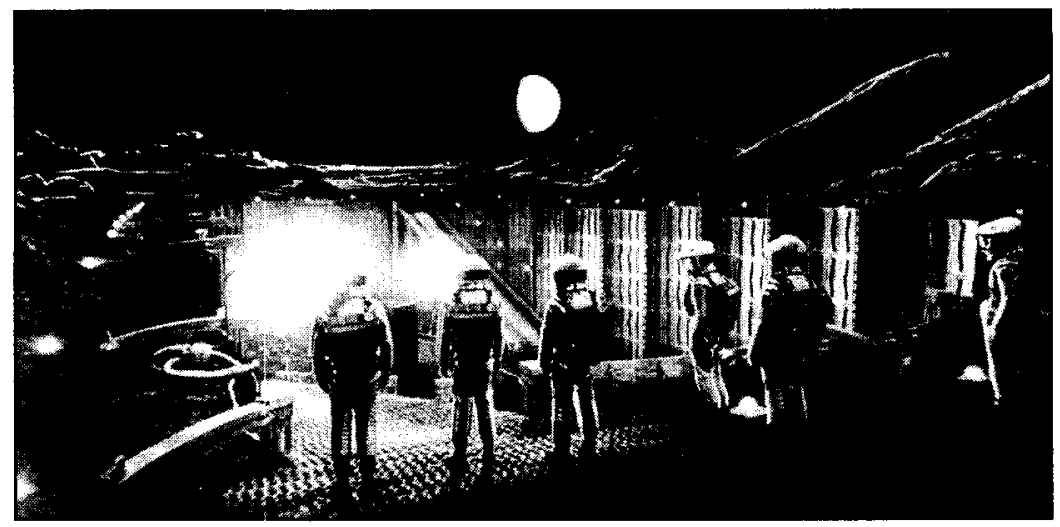

\section{1 : l'odyssée de l'espace de Stanley Kubrick (1968)}

Collection Cinémathèque québécoise

simple operation; but, most probably, its ease of use is the result of operations on the object which are not related exclusively to the position or aesthetic effect of its outline on the relief of the door. In the bathroom where David Bowman concludes his voyage in the light in 2001: A Space Odyssey and in that in which Jack Torrance experiences the merging of temporal planes in The Shining, the conflict between function and image is latent. Both rooms show uniformity in lighting and conventional relations in the distance between objects, their dimensions and colours, especially in the finishing (as one may see in the bedroom of the first film, and in the mirrored wall of the other). The panels of the Discovery are furrowed, in the interstices, by ribs revealing the profile of the walls; the apparently functional floor plan of the Overlook Hotel (exposed columns, elevators on the margins of the residential zones and beside the kitchens) is thickly covered with heterogeneous figurative markings international style, art déco, American ruralism - which share nothing with the style of a hotel which one presumes to have been designed before 1906, less than two years after Muthesius' declaration.

Ornament as plastic qualification of architecture (a paradox brilliantly expressed in baroque art) is the theme of Frank Lloyd Wright's Integral Ornament at Last!, a work which explicitly 
refers to ornament's function as an expressive motor of constructed space. This intuition, already evident in the preliminary sketches for the Imperial Hotel in Tokyo, assumes a cultural and ethical significance for Wright. Decoration renders human labour more valuable, along with the material, and makes one master of architectural space, allowing one not only to live in a building, but to know its articulations by means of visual points of reference. Ornament and supporting wall are thus reconciled: function forms the architectural space, expression characterizes it and gives it meaning, beyond style.

The absence of decoration acquires importance, for its part, in forms tied to primary requirements for survival, as in cases where misleading appearances put the life of the individual at risk: traffic arteries, hospitals, food warehouses and, in a metaphorical sense, prisons. Military architecture is the ultimate symbol of space conceived as an "empty" container of action. Decoration violates the principle which requires maximum comprehensibility for the purposes of military action and the guarantee of safety for soldiers. According to this principle, in constructions planned expressly for "conventional" war (trenches, blockhouses, casemates; modern military bases however seem to respect the same principle), the straight line rather than the curve predominates, and form identifies itself completely with function. This idea has so impressed itself on the mentality of engineers that it has conditioned battle order for more than a millennium. In the clear ordering of forces in the field, Frederick the Great saw a decisive arm for a confrontation whose moves - following the logic of a chess game - were articulated but not simultaneous. Such a conflict did not exclude, indeed it presupposed, the dignity of the combatants, both victor and vanquished.

In Barry Lyndon (1975), in a single-storey dwelling with a rectangular floor plan, Captain Potzdorf follows the phases of the battle with the French troops travelling back and forth through a narrow space in front of which - on the external wall - are cracks just wide enough to permit the blasting of firearms. Their outline, often corresponding to the framing of the shot, encloses a vast, three-dimensional, cone-shaped visual 
space; at its apex there is a soldier, protected by the greater part of the small artillery. It is worth noting that in choosing forts for the filming of Barry Lyndon, Kubrick favoured places where the succession of slits or windows follows a single line, corresponding to the vast horizon along which the confrontation between the two opposing armies takes place. Such a disposition of windows is standard, from the Middle Ages onwards, but the series of windows in Kubrick's film is shown with the camera sight line parallel to them - their succession is not shown frontally. A rhythm is thus created which determines the dramatic quality of the action (the theme is a constant in Kubrick, to the point of being a vehicle in itself of interpretation of the events) and what results is an amorphous space, theoretically infinite, in rooms where windows do not denote space but luminaristically evoke the "climate" of the events. This is the case of the windows lining the Colorado Lounge in The Shining and those in the trial scene in Paths of Glory (1957).

With equal insistence, Kubrick attributes to the staircase (another "necessary" element in the volumetric development of a building; an element which is also, in its essential requisites,

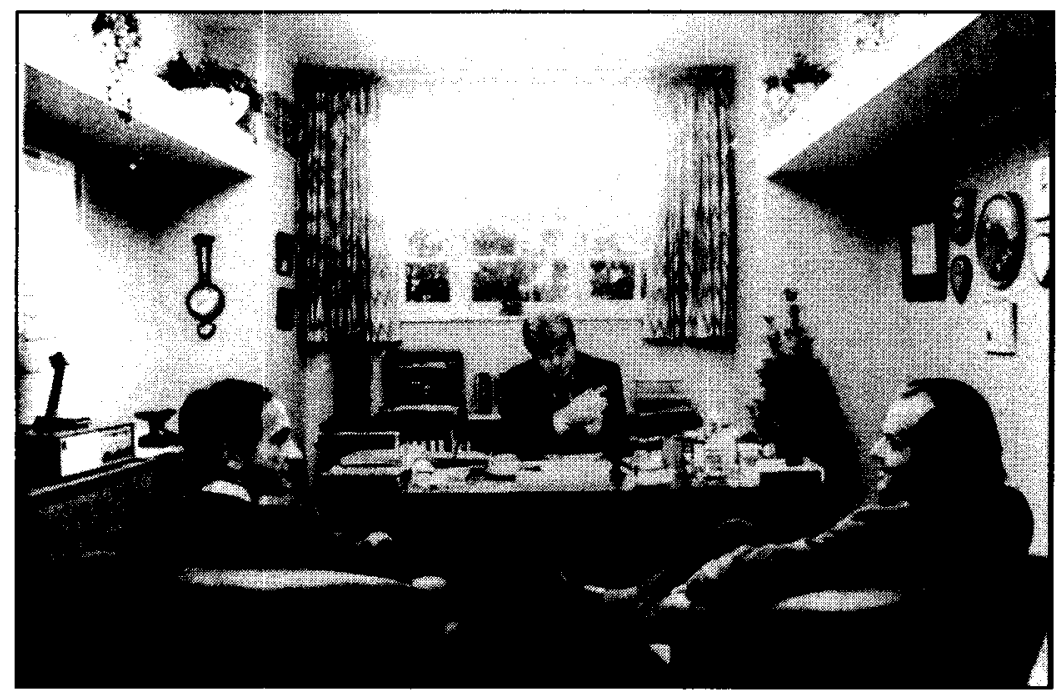

Shining de Stanley Kubrick (1979)

Collection Cinémathèque québécoise

Kubrick as Architect

121 
deprived of decoration) a function which is not only architectural, but also figuratively and narratively pivotal. The window regulates knowledge of external space and communication between worlds; the staircase brings the same qualities to the interior of the apartment. Rarely is its "utility" tied to the concatenation of events in the story or to the psychological depiction of characters. The steps of the staircase are instead - along with the corridor - a place in which the knowledge of space takes on a narrative value which is quite often cathartic. Only in A Clockwork Orange (1971) does the staircase (at the exit of the De Large household) link separate episodes: the rapid coitus to the music of Rossini and the verbal dispute with the Droogs. Different is the figurative plainness of the stairway with chessboard landings in Killer's Kiss (1955), and of the wood steps of the writer's house, again in $A$ Clockwork Orange. Here, on the contrary, elements which unleash the drama or bring about radical changes in the lives of individuals explode (a paradigmatic example is the double climbing of the folding carriage steps in Barry Lyndon: the false Monsieur de Balibari who succeeds in escaping after the game room episode; the defeated Redmond accompanied by his mother in the carriage which will carry him into exile) or set a different pace to the narration, as in the shift from a plan constructed with frontal symmetries to one with a radial symmetry.

Thus, although it is more similar to the destination of a journey than to a passage between places, the staircase is the most "narrative" architectural element in Kubrick's cinema: more so than the corridor, to which is attributed a prevalently symbolic value. It is however known that, in the architectural disciplines, the staircase is the material equivalent of human action directed to a purpose. This may be best understood if one observes that architecture unique among the arts - involves aesthetic dimensions concerning at the same time both statics and dynamics, activity and contemplation. The space of a building is "known" by those who travel through it and make use of its environments; nevertheless, the same building may be observed, be it only from the outside, in its totality. It is a subjective totality, known from the exterior, which does not depend upon the human presence inside the building. Moving along a stairway one finds oneself, in a certain 
sense, in the intermediate position of one placed before a visual progression, (concerning the subdivision into floors of a building), grasping at the same time the dimensional unity of the same building: the unity of measure which determines, along with the time necessary to travel through all the spaces, the thickness of the walls and the width of the steps.

This explains, as I have already pointed out, the crucial location of the staircase within the scene of action or its very presence in the building: but it explains, as well, the direct relationship that Kubrick establishes between the presence of a staircase and the propensity of characters to compare their own physical and psychological states with the most important space that can be travelled through in an architectural construction. The numerous persons in Kubrick's films who sit in wheelchairs, unable to climb stairs and therefore incapable of measuring themselves against space, thus acquire importance; and one understands better the origin, if not the nature, of their psychic disorders. The writer in A Clockwork Orange is wheelchair-bound in a dwelling in which he cannot live without the help of an assistant, and Sir Charles Lyndon is guided to the edge of a belvedere from which he cannot descend on his own. The steps of a staircase link (or separate) not only architectural levels and those which are habitually named - with an unequivocal identity of terms - levels of narration, but also different times and modes of story-telling. Jack Torrance utters: "Wendy, my treasure, light of my life" (the first words of Nabokov's Lolita), reproducing, in his look and the slow determination of his gestures, the behaviour of Humbert on the stairway which will be the theatre for the killing of Quilty and point of departure for the long walk backwards summarizing Humbert's descent into dissolution.

When it is not meant as a solution linking rhetorical resources (Alex's above-mentioned descent of the staircase in front of the Droogs, with the rallentando rhythm of William Tell nearly reproducing the rhythm of his footsteps on the stairs) with crucial points in the development of the drama (the meeting in the palace between Captain Dax and General Broulard, in front of a balustrade, in Paths of Glory), the most elementary scansion of spatial planes defines the differences between the 
emotional climates of the events. A trench is nothing, when looked at closely, but a long, enormous step which separates a space of relative security for the individual from the other, more ample space in which safety is put at risk. Once again, the raised position of the grandstand in Spartacus (1960) in the fight between the gladiators first united by their imprisonment in the dungeons emphasizes the contrast between a state of total and incontrovertible superiority (the physical condition of the patricians) and the primordial fight for survival which is forced upon the men in the ring. Opposed to the staircase from the volumetric point of view, the enclosure is the elementary form of spatial rationalization pursued by Kubrick up to Barry Lyndon.

The point of encounter between the two dimensions is found in the famous sequence in 2001: A Space Odyssey where a member of the Discovery crew brings breakfast on board by means of a revolving platform which permits communication between the different levels of the spaceship (a multiplication of the criteria of orthogonality which will be taken up again, as well as in the succeeding film The Shining, in another sequence in 2001 where the nucleus of the orbiting station is occupied by control rooms laid out according to differentiated, anomalous perspectives, reproducing the figurative schemes of Escher's lithographs). Quite different is Barry Lyndon, even in scenes where the window is an element explaining previous or contemporary events (the announcement of Brian's accident made while Redmond is shaving). It is a rather sparing film in its depiction of staircases, the triumphant architectural unit up until the eighteenth century. The horizontal, which dominates in Barry Lyndon, from the movements of machines (rectilinear or circular) to organized space (pools, countrysides, battle formations) furthermore suggests that the individual again becomes the protagonist in the rhythmic articulation of space (in the furnishings, in the matching of buildings as volumes emanating light from their facades, in the natural landscape) and in the knowledge of space itself. Following a pattern characteristic of 2001: A Space Odyssey (the identity of function and form in common objects, such as Floyd's fountain-pen or the food tray), Barry Lyndon assigns the cognitive process to the ordered outline of an interior that is for 
the most part quadrangular and spare (as in the duel between Redmond and Bullingdon) and of a nature cultivated by man with the aim of directing one's gaze and connoting movements which, by themselves, suggest the natural and justify its transformation into architectural material. The philosophy of landscape gardening accepts verticality as an exceptional fact, tied to a space which subordinates action to the image (along the outline of the horizon) rather than activating it (as happens in the environments surrounding Kubrick's enclosures: the wood doorjambs in Spartacus, the corners of the ring in Day of the Fight (1950), the grenadiers in Barry Lyndon). The ideal architect of nature is not, according to Inigo Jones and Capability Brown, one who conceives the wood as a giant hedge to be observed from afar or which circumscribes a valley and frames it on a level with a genre scene. Such emphasis distinguishes the art of the English garden from that of the Italian, of Renaissance origin, conceived as a direct and undisputed assertion of symmetry. The synmetrical principle of the landscape gardener is not the vegetal arabesque, but rather the possibility of recognizing the object, the choosing of figurative points of reference for which human intervention is at the same time evident and hidden by the "natural" arrangement of a brook or a group of birches. The natural environment charges architecture with significance; the atmosphere brings it closer to the tonality of the spatial plot, essential punctuations in the last paragraph of every chapter ending; with an identical sentence: the Lyndon residence, now touched by fleeting gusts of wind, now lost in the morning mist, now impregnated with the afternoon light which the eighteenth-century English appreciated in Bellotto.

The identity in Barry Lyndon of structure, decoration (the tree as ambivalent element in the specification of inhabited space) and narrative function divides in two in The Shining, a film about duration which presupposes Barry Lyndon, and an experiment with time realized thanks to a double radicalization of the concept of space: one geographical the isolation of the Overlook Hotel from the world, reproduced in the hedge maze; an intermediary between English landscape architecture and the abstraction of the Roman garden), and one concerning time (the 
seasons of Barry Lyndon; a snow which plastically requalifies the hotel and which reconstructs distances within the maze); but the relationship between natural space and architectural perception of time has not changed. A corridor of light denotes the temporal vector (along with human respiration) in 2001: A Space Odyssey, a corridor of vegetation denotes the approach of Halloran in the snow-cat enveloped in semi-darkness.

The corridor guides human movement, but it does not establish an unambiguous relationship with space, which for this reason assumes uncontrollable forms and from which the points of reference necessary for the individual's orientation are absent. The sensation is taken up again, in the interiors, by the multicoloured decorations (opposed to the chromatic uniformity of the labyrinth) in the wallpaper and the hotel carpeting, abstract geometrical decorations, characteristically directed in The Shining towards the exaltation of the infinite bidirectionality of geometric motifs on the walls and carpets and the primary colours brought together in the Greek key design of the floors in the corridors. The hotel decoration thus becomes, in appearance, superimposed on the structure of the building, but in fact conditions its image for those who travel through its spaces entrusting themselves to the only certain point of reference: a room number. The maze is already, on its own, an arabesque, a "decoration," an "empty" architecture which organizes and imposes a useless journey; nevertheless, we are concerned here with a compulsoriness which directly affects the perception of time: Jack Torrance dies because he has not had time to find the exit - and has not reached the center - of the maze, while Danny saves himself because he finds in the apparent emptiness of the vegetal corridors a system of visual references tied to movement and time: footprints in the snow. An imprecise, transient, irregular sign: recognizable exactly for this reason in the changing but identical rhythm of right angles, in the infinite and limited space of an intricate and abnormal architecture.

A crucial, dynamic symbol of the horror-movement equation in The Shining, the tennis ball made to roll in front of Danny near Room 237, introduces a further narrative property of the architectural presence in Kubrick's cinema: the architectural 
construction as a sign of time. There were traces of this interpretation in the presence of the word "Home" at the entrance to the house in which Alex, raping the wife of the writer, begins his own voyage through time (a voyage that foresees his successive return to the same building and consequent attempted suicide; the dialogues of $A$ Clockwork Orange frequently emphasize, on the other hand, the symbolic value of the term). Alex's story is an odyssey which unfolds in the environments of four principal "dwellings" (excluding the medical institution where the youth, undergoing the Ludovico treatment, is forced to watch films, and not taking into account the hospital: final, specular ends of opposing trials); we see an aerial view of the prison, the temporal keystone of the film, and we identify its crossed arms (a symmetry tied to the control of violence). Of the other dwellings we have but meager, plastic specifications, sufficient however to infer differentiated cultural (and temporal) connotations for each one. The house of Alex's parents, in conformity with the dictates of popular residential buildings (like the Boulder house in The Shining; and the banal layout of Halloran's summer residence), is an apartment painted in garish colours alternating with unbearable wallpapering. The arrangement of the rooms is conventional (a corridor connects rooms of more or less identical size, distinguishable one from the other thanks only to a portrait of Beethoven or a few plastic flowers); the decor is an "international" modern kitsch, which triumphs in the living room portraits and whose "style" follows closely that of the specular nudes in Halloran's bedroom in The Shining. In the residence of the cat lady, a brief staircase leads to the presence of a number of felines occupying the womans' gym; our structural knowledge of the building is limited to the central room and the exit (a few steps, in baroque style, are the scene of the attack on Alex with a milk bottle). The residence of the writer is an architectural study of symmetry and rhythm: a floor plan that we imagine as rectangular with two wings divided by a long raised section, two sets of wood stairs behind the living room and the dining room with its glass table, sources of direct light (reflected in the entrance mirror) often coming from below (from the table where Alex is interrogated while eating; the solution is 
similar to that of the Gold Room bar in The Shining). Each environment produces - even in the sounds which are produced there - a situation or a psychological conflict or, lastly, a different rhythm in the flow of time: amorphous in the case of the De Large house, slow at the writer's home, vertiginous for the cat lady. In all three cases, the expressive dynamics of space derive, at least in part, from the material dynamics (plastic for the parents, fabric for the cat lady, wood for the gifted writer; this is also the case in Barry Lyndon with the wood floor on which Brian walks, wearing his brother's clogs, in front of the chamber orchestra). I have already alluded to the role of the staircase in Kubrick's houses (also evident in the house of Lolita's mother and outside the hotel in which the fleeing lovers stay). The other constant, almost obsessive architectural presence is the corridor: omnipresent in his films, from Paths of Glory to the film in which the concept of home, materially absent, is substituted by the gigantic bulk of the spaceship : 2001: A Space Odyssey. All of the material structures of the human adventure in the light are, when reduced to their essentials, corridors. The Discovery, planned like an oblong warehouse of data and services (at its end is a sphere, which we identify with the command center, the "brain" of the spaceship), is composed of modules whose parallelepiped shape finds its corresponding form not only in the monolith (an abstract form apparently lacking in real dimensions and yet furnished with edges and thin sides like the points and lines of a geometrical treatise) but also in the excavations on the lunar surface: a quadrangular outline with two symmetrical ramps, also specular, which lead in a gentle decline to the other mysterious object touched by the astronauts in a primordial discovery of measure. The corridor, which in 2001: A Space Odyssey defines the modes and times of narrative succession, is in the form of a parallelepiped - whose greater side is hypothetically infinite. In a space where the perception of time is entrusted to clues altogether different from the mere presence of a clock or the observation of the stars, the corridor gives to time itself - otherwise "absent" - an uncertain objective connotation which is nevertheless preferred to the total absence of any system of reference. 
The corridor is one of the most "superfluous" architectural elements in terms of function (one neither lives nor carries out any activities there); its surface leads, on the other hand, to significant behaviours or to places charged with symbolic value. In Ionic architecture, internal colonnades and ambulatories occupy at times more than a third of the entire surface area of the temple; antecedents of the corridor, unknown as an organism tied to the plans of late sixteenth-century civil housing, they are also found in the plan of the protochristian basilica, characterized by a wide space which may be travelled through only frontally as regards the place of bodily sacrifice and the conquest of eternity. The purpose of the corridor is always "beyond" its existence: the "wheel" of the record shop in A Clockwork Orange — taken up in the circular discographic symbol (the English record label Vertigo), with curved lines arranged in eccentric groups, on the sales counter - brings us to the rapid, agitated gestures of Alex in his bedroom; the aerial "corridor" in which the deadly aircraft of Dr. Strangelove leads to nuclear catastrophe; Lord Bullingdon travels through, as in a corridor, the entrance rooms of the paternal residence before challenging Redmond Barry to a duel; a corridor is the punishment inflicted on the Prussian soldiers in the goal of improving their efficiency in battle, and it is the area in which the horses in The Killing (1956) run (several times, but in the same moment) in their fight for supremacy. A last, unobvious corridor, in Lolita (1962), introduces Humbert to the first "shining" of Kubrick's cinema. Having made a few steps, the writer finds himself in front of the bathroom after having reflected upon the possibility of killing his wife. He opens, with one hand on the left, the door which is ajar. The tub is empty. Humbert already regrets his intentions, but the irreparable has already happened a short distance away, on the street, even before his gaze can fall on the white enamel of the tiles which cover the room.

The same happens in The Shining. Jack Torrance opens the door of Room 237; he then pushes open the bathroom door with one hand, on the left, and sees nothing in the tub. The camera lens then turns to Jack who observes, stunned, the humid, greenish colours of the environment. The tub is now 
occupied by a female apparition who will transform into an image of senile decay and a sore-ridden spectre of sexual disgust. The light thus seems to have travelled through an invisible corridor formed by the two shots of the empty tub and that of the woman. In the middle there is the gaze of Torrance, shortly thereafter reflected in mirrors in which he will find an "explanation" of the apparition. An explanation, and many questions. Why does the spectre come out of the tub in a form of splendid nudity and then become a living cadaver in a state of putrefaction? Why does Jack "see" it only on the second look, "parallel" to the preceding one? Why, finally, does the apparition in front of him travel backwards through a temporal sequence? So it would seem, in fact, on a careful examination of the succession of visions concerning the spectre. Its first maleficent incarnation, "created" by the mirror, reappears in Jack's instantaneous detachment from the decomposing body; but the tub again becomes the protagonist (and with it the entire room, from that moment travelled through backwards by Jack, now breathless) of other mirages. The decrepit female body seems as if to "reappear" or "return" to the tub, and seems to carry out the same gesture of the young woman, that of delicately moving the curtain which hides the flesh.

One must remember that another apparition (this time indirect) in a bathroom is found in the opening of the film; the mirror is of more modest dimensions, but the colour of the tub and the curtain which conceals it is identical. We will refer further on to the third, fundamental bathroom of The Shining, the public one adjacent to the Gold Room; the toilets of Boulder and Room 237 are sufficient, on their own, to remind one of a problem already raised beginning with the bathtub-toy which appears in Killer's Kiss and which is reformulated with enigmatic precision in Barry Lyndon. The poem recited by a lady in waiting to a woman in a bathtub, Lady Lyndon, hypothesizes the presence of an ideal corridor (with the walls "l'un à l'autre opposés") in which the masonry is replaced by mirrors ("miroirs ardents"). A luminous ray, whose source is undefined, starts from the center of the poetic corridor and illuminates a subject who observes, placed - also ideally — in the same position. The bouncing of 
the ray of light from one wall to another of the corridor (lines which "s'accroissent, s'embellissent") makes it such that the light does not illuminate anything but itself, in an interminable sequence of reciprocal "illuminations" ("shinings") of the nearly immaterial, indistinct entity which is light itself. A theoretically punctiform source of light, illuminating perfectly parallel, specular surfaces, would give form to an object, itself visually multiplied to infinity and therefore reproduced, in all the other parts of space included between the two mirrors, as if the light were emitted not from one, but from an infinite number of places simultaneously. An object capable of behaving like this luminous unity should therefore "observe itself" from all possible angles, in places and times (imperceptibly) different from that in which the first luminous emission takes place.

The image rnultiplies, changes consistency and form in the times created by the proliferation of the light. The fantastic apparition which presents itself to Jack Torrance's eyes is “identical" to the others, neither antecedent nor successive to that which is the first, but only in the logical order presented by the temporal vector of the film, one of many, not even favoured by respect for the most immediate temporal sequentiality.

The image of time shapes or dissolves the awareness of space. Once the references to "before" and "after" have been eliminated through the workings of light, it is the light itself which renders multiform — this time quite "unknowable" — travelled-through and lived-in space. For this reason light is the origin of terror in The Shining: for this reason it is in the light, and not in the torpor of shadow so dear to the Gothic novel, that the horror of space presents itself as existence, in the same point, of several presences and several times in collision. In the bathroom mirrors, in the direct light — reflected by ample white surfaces - of the toilets ("neutral" environments, where sound spreads in unnatural concretions), the consciousness of time is replaced by a neutralization of perception. In every bathroom, in every corridor (and in the maze, a corridor which leads to nothing if not its own self-perpetuation), light and sound spread in a once again infinite circuit. In the maze this impression is reinforced by the fact that individuals such as Jack Torrance or 
Wendy must recognize not only "active" time, useful for reaching the center, (in The Shining in the form of a rectangle) but also "retroactive" time, without which the memory of space is nothing but an empty accumulation of annotations and turning points. A bathroom is not made to be travelled "through"; but the lessening of faculties — such as hearing - which derives from it has a negative influence on the "understanding" of a materially limited space. The sonic reverberations of Alex who sings "Singin' in the Rain" and of Jack Torrance who, beside a bathroom, mocks Danny whimpering that "maybe we should take him to a doctor" (an event which has already taken place) are equivalent, in a weakened form, to the luminous reverberations; these also refer to the simultaneous experience of several temporal scansions, of mutually exclusive events. There is no difference between the bathtub in which Alex is immersed by the Droogs in an interminable shot punctuated by the muffled noise of the blows he is receiving, and the bathtub in front of which Bowman, in a space suit, encounters eternity.

The comparison is more meaningful when one looks at the moment in The Shining when Torrance, still dirty with Advokaat, speaks to Grady and is in reality engaged in a monologue on the circular form of time ("you have always been the hotel watchman"). Kubrick speaks of a room taken from a hotel designed by Wright in Arizona. It could be the Arizona Biltmore (1927) or the Elizabeth Arden Resort Hotel, the Phoenix "Sunlight," conceived in 1945 according to construction principles characterized, once again, by the predominance of the straight line (where, therefore, the meeting of floors has an expressive significance equal to the orthogonal poetics of Taleysin or to the entire Japanese period) and in which, nevertheless, the horizontal form prevails over all others by far. Also horizontal is the semicircularly shaped organism jutting out from the facade of the "Sunlight," as if to demonstrate that its emergence from the crystalline perimeter of the building is the only relief, consciously isolated, on an almost entirely smooth surface. This theme is found formulated in identical terms in numerous designs by Muthesius (verandas, living rooms, some atriums), whose mature production coincides stylistically — as 
one may verify observing the facade of the Feudenberg house (1907-1908) -- with the form of the Overlook Hotel: a series of jutting structures, of various dimensions, joined to a central body - on the exterior - by strongly sloping lines (the roofs), to meet functional requirements (falling snow) and following a cultural heritage (American ruralism; according to Muthesius, neogothic and the model of the englisches das Haus). There is no trace, then, of the curved line; as is also the case in the bathroom of the Gold Room (the architectural monolith of The Shining), in the layout, in the arrangement of the mirrors and in the rigorous alternation of red and white in the tiling. The bathroom itself is, in its own way, a corridor, as is demonstrated by the specular shots of Jack and Grady beside the reflecting surfaces of the washbasins. As in the bathroom in A Clockwork Orange, the noises of the "outside world" are far away, almost unrecognizable (one barely distinguishes the word home, sung as a place of protection for lovers); as is unrecognizable the architectural totality of the Overlook Hotel. The identification of space and story with the puzzle thus returns - a theme already emphasized in the voice-over in The Killing - a puzzle of which we know the series of single elements and which we cannot reconstruct, at least not without attributing to the single portion of space a new meaning, contemporary with the preceding one.

But The Shining is such a perfect puzzle that every piece contains not one, but countless meanings; and the junctions between the pieces placed beside each orher are, in fact, invisible. The Overlook Hotel is perceived as an infinite but concluded totality. Each service area, each sector of the hotel seems to obey the most sophisticated functional requirements, even if at least for the observer - it is practically impossible to reconstruct the plan of the building and each room, each corridor seems as if seen for the first time. As in the maze, this is not necessarily so, but for those who find themselves within the walls of the Overlook, or among the hedges of the maze, the sensation is inevitable. The succession of corners and corridors is "predictable" (we know that, at a certain point, a wall will turn a corner, or will open up into a doorway), but this is useless 
seeing as we know nothing of the rhythm with which doors and corners will alternate: and we suspect that we will never know. In such conditions we can only have recourse to the sound of the heartbeat : the only regular noise heard by Jack Torrance in Room 237 and by David Bowman - who breathes with regular intervals - in the memory room of $\mathrm{Hal}$. The ball which, after having "circularly" travelled through a finite universe, stops in front of Danny (we could say, following a relativistic suggestion, that it was Jack who had thrown it shortly before from the end of a corridor), is the only means remaining for the protagonist of The Shining - by now prey to crises of melancholy - to extricate himself from the uniform (and multiform) flow of time: made to bounce against the walls of the Colorado Lounge, the tennis ball reproduces the heartbeat in the middle of the interminable blowing of the storm which isolates the Overlook from other universes. Rhythm segments time and renders it perceivable and knowable. When this residual possibility is absent (in the maze, on the floors of the Overlook Hotel not heated during the winter) every strategy is in vain. No rhythmic element may be inserted in the plan of the great hedge constructed according to a program based - as a game - on absence, unpredictability, uniformity, symmetry and the elusion of all cadence.

The only coordinates available to Jack Torrance for escaping the sense of "infinite" uniformity in his environment are little more than clues involving the form of the building and the relationship between the individual and the volumes constructed in a space that is unrecognizable because it is not differentiated; in other words, a space in which the impression of rhythm does not help one to identify new elements and invariables in the development of the architectural construction. The reactions of the protagonist to the environment in The Shining (including here the mania for ordering in regular and symmetrical groups of words the indistinct, "infinite" proceeding of the novel on eternity written in the Colorado Lounge) obey a primordial instinct, frustrated where there is no visible or audible difference between one space and another and in which - as far as the dimensions of inhabited space are concerned - the volume of 
the environment is disproportional to the number of persons which inhabit it (the "shining" of the Gold Room crowded with guests is an indication of the weight which the problem has taken on for Jack). This disproportion is one of the causes of the depressive syndrome - parallel to the blocking of the capacity to create and "aggregate" meanings out of the shapeless flow of cerebral energy - typical in the man of genius, and it is the origin of Jack's crazy gesturing in the most vast corridors of the Overlook Hotel. The muscular spasm (although "uncontrolled" by its very admission) is the ultimate resource of the organism oppressed by isolation in a space which is perceived as closed and, at the same time, polymorphous; furthermore, this identifies the sudden opening of the arms (as the staccato of the strings emphasizes, in Penderecki, for Jack's last voyage in the Gold Room where the hours - wandering hours - float in the void) with the attempt to grasp a rhythm - which is not a rhythm, because it expresses itself in an isolated gesture - with the time, otherwise "infinite," of the journey.

Neither the hotel nor the maze are consciously intelligible spaces for the Torrance family; we have two overall pictures of them, at the beginning of the film and in the model in which we see Wendy and Danny wandering in search of a fictitious center, which is nothing if not the meeting point of all possible itineraries (of all imaginable times for the Overlook), the zone before which there are countless backwards itineraries towards the entrance (the moment of choosing, the first move in the chess game with space) and where Danny succeeds in recuperating an unambiguous temporal dimension only by exploiting a visual "rhythmic" element (footprints in the snow), a fleeting decoration of solidified water. The presence of ornaments at the edges of space favours the success of Jack's projects (the killing of Halloran) in the hotel; their absence decides their defeat, transforming him into a block of ice which crystallizes all time. The "integral" decoration of which Wright spoke, and which Muthesius identified with the form of the building, has thus become the building itself, replacing it in the moment in which the subject has ceased to acquire consciousness of space when travelling through it: decoration as rhythm, then, a symmetrical 
organization of biological forms as a cardinal sign of time. Time articulated by a corridor, a staircase, a window, a bathroom in just as many pauses, accelerations and nuclei of duration, which make themselves stone and abstract material for the art of construction, those which Goethe suggested to Eckermann when he spoke of architecture as a form of "frozen music."

\author{
George Eastman House, Rochester (NY) \\ Translated from the Italian by A. Blake Trecartin
}

NOTES

1 This text, translated from the Italian by A. Blake Trecartin, was published in Gian Piero Brunetta (ed.), Stanley Kubrick. Tempo, spazio, storia e mondi possibili (Parma: Pratiche Editrice, 1985, p. 201-218). 